\title{
Increased hypoxia-inducible factor 1a expression in lung cells of horses with recurrent airway obstruction
}

\author{
Marie Toussaint ${ }^{*}$, Laurence Fievez ${ }^{1}$, Christophe J Desmet ${ }^{1}$, Dimitri Pirottin ${ }^{1}$, Frédéric Farnir ${ }^{2}$, Fabrice Bureau ${ }^{1}$ and \\ Pierre Lekeux ${ }^{1}$
}

\begin{abstract}
Background: Recurrent airway obstruction (RAO, also known as equine heaves) is an inflammatory condition caused by exposure of susceptible horses to organic dusts in hay. The immunological processes responsible for the development and the persistence of airway inflammation are still largely unknown. Hypoxia-inducible factor (Hif) is mainly known as a major regulator of energy homeostasis and cellular adaptation to hypoxia. More recently however, Hif also emerged as an essential regulator of innate immune responses. Here, we aimed at investigating the potential involvement of Hif1-a in myeloid cells in horse with recurrent airway obstruction.

Results: In vitro, we observed that Hif is expressed in equine myeloid cells after hay dust stimulation and regulates genes such as tumor necrosis factor alpha (TNF-a), interleukin-8 (IL-8) and vascular endothelial growth factor A (VEGF-A). We further showed in vivo that airway challenge with hay dust upregulated Hif1-a mRNA expression in myeloid cells from the bronchoalveolar lavage fluid (BALF) of healthy and RAO-affected horses, with a more pronounced effect in cells from RAO-affected horses. Finally, Hif1-a mRNA expression in BALF cells from challenged horses correlated positively with lung dysfunction.

Conclusion: Taken together, our results suggest an important role for Hif1-a in myeloid cells during hay dust-induced inflammation in horses with RAO. We therefore propose that future research aiming at functional inactivation of Hif1 in lung myeloid cells could open new therapeutic perspectives for RAO.
\end{abstract}

Keywords: Hypoxia inductible transcription factor-1, Recurrent airway obstruction, Inflammation, Lung, Horse

\section{Background}

Recurrent airway obstruction (RAO) or heaves is a wellknown respiratory disease in horses that shares any pathophysiological similarities with asthma in humans [1-3]. RAO is a severe, potentially debilitating, chronic inflammatory airway disease typically affecting middleaged horses. Acute exacerbations are characterized by neutrophilic airway inflammation, coughing, periods of labored breathing at rest and exercise intolerance due to bronchospasm and mucus accumulation in the airways [4]. It is initiated following exposure to organic dusts, molds, and lipopolysaccharides (LPS) in hay [5]. Periods

\footnotetext{
* Correspondence: M.Toussaint@ulg.ac.be

'Laboratory of Cellular and Molecular Physiology, GIGA-Research and Faculty of Veterinary Medicine, University of Liège, B34-Avenue de l'Hôpital, 1, 4000, Liège, Belgium

Full list of author information is available at the end of the article
}

of acute exacerbation are interspersed by periods of remission, when horses are kept away from the causative environment [3]. The immunological processes responsible for the persistent airway inflammation are still largely unknown [6]. RAO is thought to result from an aberrant immune response orchestrated by antigen-specific $\mathrm{T}$ lymphocytes via the secretion of pro-inflammatory cytokines. Whether these $\mathrm{T}$ lymphocytes have a type 1 or type 2 phenotype and cytokine secretion profile is still a matter of debate [7-11]. Although little studied so far, innate immune mechanisms, which constitute a central interface between external stimuli and the adaptive immune system, may also play an important role in the pathophysiology of RAO.

Hif1 is an essential regulator of adaptation to low oxygen levels [12]. Hif1 is a heterodimer composed of an oxygen-regulated $\alpha$-subunit and a constitutively expressed

\section{Biomed Central}


$\beta$-subunit. In general the abundance of $\alpha$-subunits is primarily regulated by a family of prolyl hydroxylases (PHD). In normoxia, PHD is activated and directs the degradation of the $\alpha$-subunit by the ubiquitin-proteasome pathway [13].

Under hypoxia, PHD activity decreases, which leads to the stabilization and translocation to the nucleus of the $\alpha$-subunits which heterodimerize with the $\beta$-subunit. This dimer recognizes the hypoxia response elements (HREs) to induce target gene expression. Hif1 activity is primarily regulated by the abundance of the Hif1- $\alpha$ subunit [14]. Since Hif1 is highly involved in the adaptation of cellular metabolism to hypoxic condition, it was also proposed that Hif1 is an important promoter of inflammatory responses, which most often require innate immune cells to adapt to oxygen-deprived inflammatory environments $[15,16]$. Indeed, it was found that Hif1 regulates many pro-inflammatory genes such as tumor necrosis factor alpha (TNF- $\alpha$ ), interleukin-8 (IL-8) and vascular endothelial growth factor A (VEGF-A) [17]. Hif1 was furthermore found to engage in cross-talk with another major pro-inflammatory pathway, the Nuclear Factor (NF)- $\kappa B$ pathway [18]. Although most studies focused on hypoxic conditions, Hif may promote inflammatory functions of myeloid cells also in normoxic conditions $[19,20]$. Indeed, Hif1- $\alpha$ may be indirectly activated in myeloid cells by pro-inflammatory stimuli such as LPS and the pro-inflammatory cytokine TNF- $\alpha$ $[21,22]$. After LPS or cytokine stimulation, NF- $\kappa B$ promotes Hif1- $\alpha$ gene transcription, promoting its accumulation in spite of post-translational degradation [18,23]. In myeloid cells, hypoxia through decreased Hif1- $\alpha$ degradation and inflammatory stimuli through increased Hif1- $\alpha$ transcription may synergistically potentiate the activation of Hif1.

We hypothesized that, because myeloid cells are implicated in RAO, and because Hif1 is a major regulator of the pro-inflammatory functions of myeloid cells, Hif1 could play a role in the pathophysiology of RAO. To test this hypothesis, complementary in vitro and in vivo approaches were undertaken.

Firstly we assessed in vitro expression of Hif1 mRNA and its target genes in horse myeloid cells in response to hay dust. Secondly, in vivo, we analyzed whether hay dust-induced lung inflammation in RAO-affected horses correlated with increased Hif1 expression in lung myeloid cells. Finally, we tested whether increased Hif1 expression in BALF myeloid cells correlated with clinical variables in RAO-affected horses.

\section{Results}

Hif1- is expressed basally and upregulated by hay dust in horse myeloid cells

We first tested the presence of Hif1 in horse myeloid cells and assessed hay dust-induced Hif1 activation in these cells. Relative Hif1- $\alpha$ mRNA expression between excipient- and hay dust-treated monocytes was assessed 1,2 and 4 hours after stimulation. The Hif1- $\alpha$ mRNA was expressed basally and this expression was significantly higher in stimulated than in unstimulated-cells $1 \mathrm{~h}$ after the beginning of the treatment, and maximal induction was achieved after a $2 \mathrm{~h}$ incubation period. At $4 \mathrm{~h}$, Hif1- $\alpha$ expression was maintained at a high level (Figure 1).

\section{Hay dust induced pro-inflammatory genes associated} with Hif1-a activity in equine monocytes

We next aimed at determining whether hay dustinduced Hif1- $\alpha$ mRNA upregulation may result in increased Hif1 activity in equine monocytes. Hay dust suspensions induced a significant increase in VEGF-A, IL-8 and TNF- $\alpha$ expression in equine monocytes as compared with excipient-treated monocytes (Figure 2). We observed strong positive correlation between Hif1- $\alpha$ induction and cytokine expression (Hif1- $\alpha$ /VEGF-A: $r=0.92 ; \quad$ Hif1- $\alpha /$ IL-8: $r=0.86 ;$ Hif1- $\alpha /$ TNF- $\alpha: r=0.81$ ). Suggesting that the in vitro induction of cytokine expression was dependent on Hif1- $\alpha$ activity, noscapine, an inhibitor of the stabilization of Hif1- $\alpha$, when added to the culture $1 \mathrm{~h}$ before challenge with hay dust, inhibited the induction of VEGF-A and IL-8. However, a lower effect of noscapine was observed for TNF- $\alpha$. For IL-8, VEGF-A and TNF- $\alpha$, some significant differences were still seen between excipient- and noscapine/hay dust-treated groups at all-time points tested. These data support that during hay dust stimulation, Hif1- $\alpha$ was partially required for VEGF-A and IL-8 expression

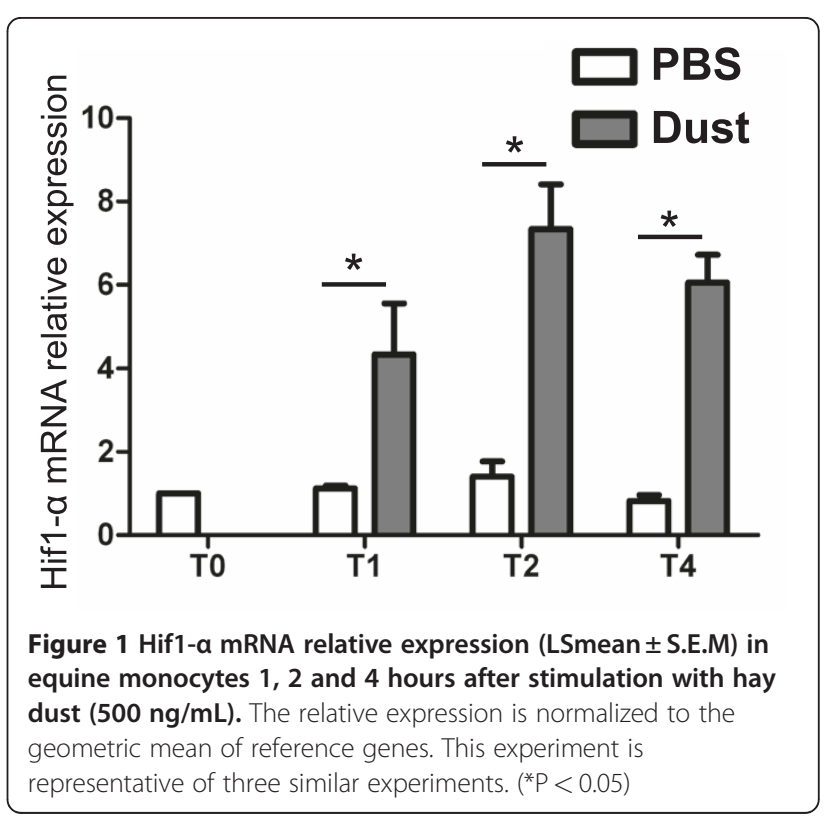




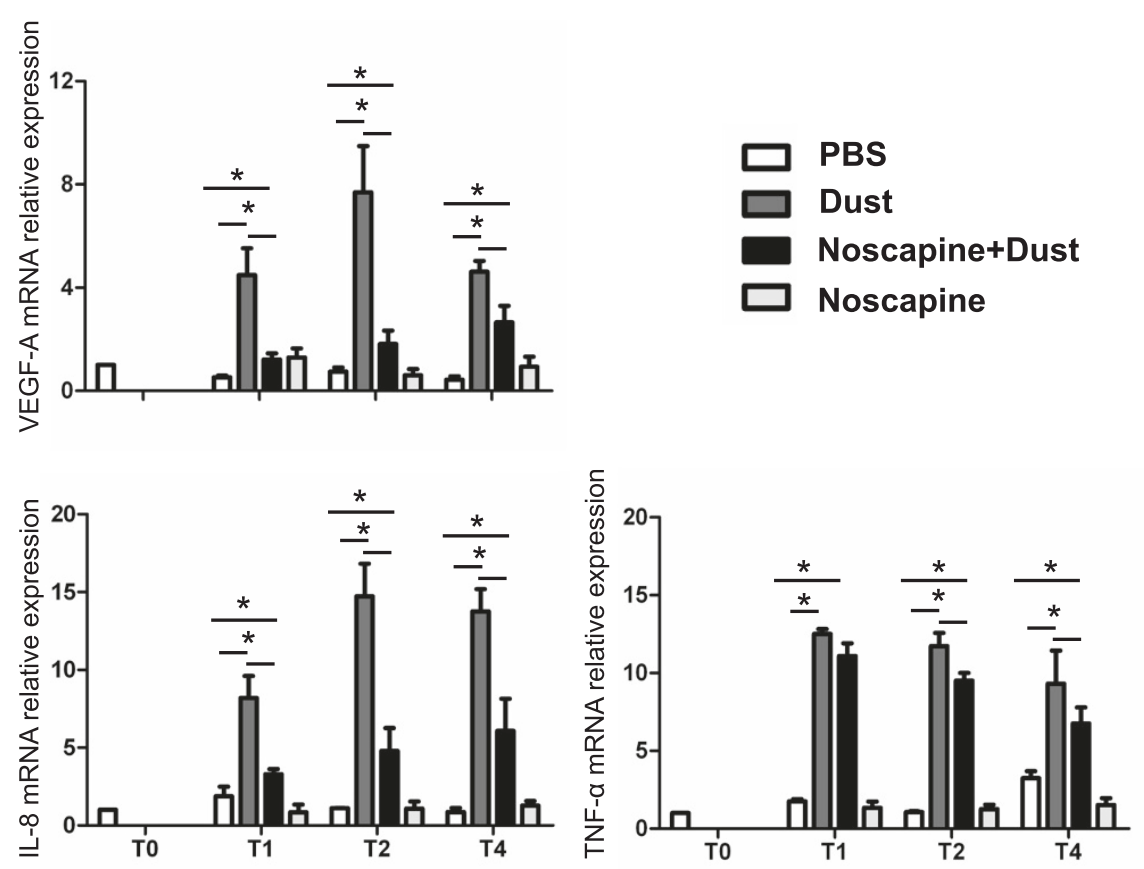

Figure 2 VEGF-A , IL-8 and TNF-a mRNA relative expression (LSmean \pm S.E.M) in equine monocytes 1, 2 and 4 hours after stimulation with a hay dust suspension. Alternatively, cells were treated with noscapine $(150 \mu \mathrm{M})$ one hour before stimulation with the hay dust suspension. The relative expression is normalized to the geometric mean of reference genes. This experiment is representative of three similar experiments. $\left({ }^{*} \mathrm{P}<0.05\right)$

in equine myeloid cells, whereas TNF- $\alpha$ induction was less dependent on Hif1. Noscapine alone had no effect on the expression of these three cytokines in equine monocytes (Figure 2).

\section{Horse clinical status assessment}

Clinical scores were significantly different between both the healthy and RAO groups after dust exposure (Figure 3). In the BALF, neutrophil percentage was significantly increased in both healthy and RAO horses following hay dust challenge. However, challenged RAOaffected horses showed significantly higher neutrophil percentage than challenged healthy horses. After the challenge, the percentage of alveolar macrophage (AM) in the BALF was significantly decreased in RAO-affected and healthy horses but the decrease was significantly higher in RAO-affected horses than in healthy horses. No significant differences were observed between the percentages in lymphocytes and other cell types. After dust exposure, arterial blood oxygen partial pressure was significantly decreased in RAO-affected horses when compared to healthy horses. The most sensitive value of impulse oscillometry for RAO-affected horse evaluation, $\mathrm{X}_{5} \mathrm{H}_{\mathrm{z}}$ was significantly different between $\mathrm{RAO}$-affected horses and controls after challenge. Clinical values for each horse are shown in Table 1.
Increased Hif1-a mRNA expression following hay dust challenge in BALF cells of healthy and RAO-affected horses

To assess whether our in vitro observations may translate in vivo, we analyzed whether hay dust-induced lung inflammation in RAO-affected horses was accompanied by increased Hif1 activity in lung myeloid cells. We first compared the relative Hif1- $\alpha$ mRNA expression levels in BALF cells of unchallenged and hay dust-challenged healthy and RAO-affected horses. No statistically significant difference in Hif1- $\alpha$ expression was observed between unchallenged healthy and RAO-affected horses (Figure 4). Hif1- $\alpha$ mRNA levels significantly increased in both healthy and RAO horses following hay dust challenge. However, challenged RAO-affected horses showed significantly higher Hif1- $\alpha$ mRNA levels than challenged healthy horses.

Hif1-a-regulated cytokines are overexpressed in the BALF cells of RAO-affected horses during crisis

Next, the expression of Hif1 target genes was measured in BALF cells from hay dust-challenged or unchallenged healthy and RAO-affected horses (Figure 5). No statistically significant difference in VEGF-A, IL-8 and TNF- $\alpha$ expression was observed between the unchallenged groups. However, we observed that VEGF-A, IL-8 and TNF- $\alpha$ gene expression was upregulated following hay 

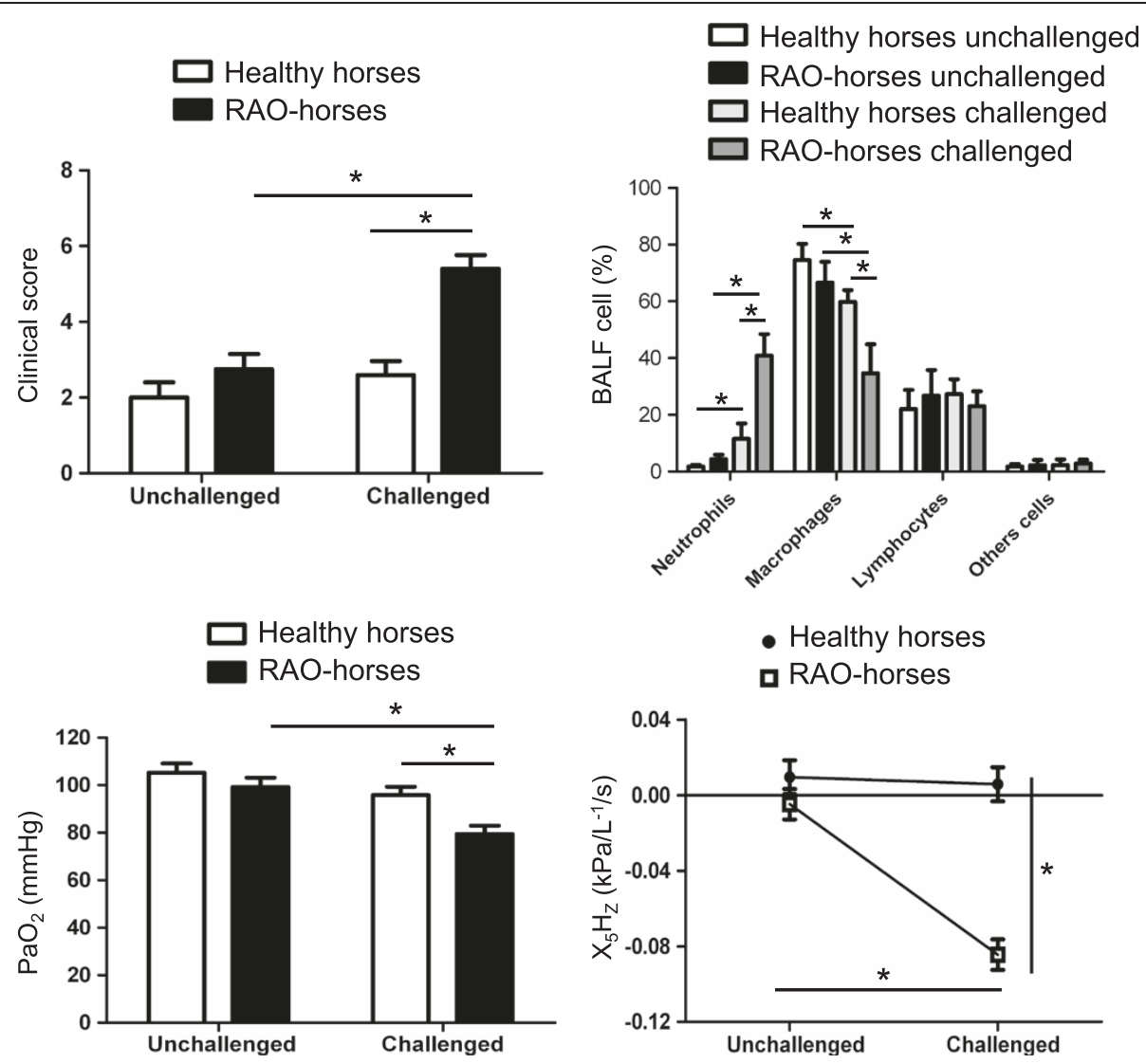

Figure 3 Clinical parameters evaluated in vivo in unchallenged and challenged healthy and recurrent airway obstruction-affected horses. Clinical score, percentage of cells in bronchoalveolar lavage fluid, arterial pressure of oxygen $\left(\mathrm{PaO}_{2}\right)$ and lung function $\left(\mathrm{X}_{5} \mathrm{H}_{2}\right)$ were compared between the groups. This experiment is representative of one protocol performed with five heaves-affected horses and four healthy horses ( ${ }^{*} P<0.05$; RAO: recurrent airway obstruction).

dust challenge. IL- 8 and TNF- $\alpha$ mRNA expression were significantly increased in both healthy and RAO-affected horses upon challenge, whereas VEGF-A levels was upregulated in challenged RAO-affected but not healthy horses. We also observed positive correlations between Hif1- $\alpha$ mRNA expression levels and expression levels of its target genes (Hif1- $\alpha$ /VEGF-A: $r=0.86$; Hif1- $\alpha /$ IL-8: $r=0.85$; Hif1- $\alpha /$ TNF- $\alpha: r=0.78$ ).

\section{Correlation between Hif1- $\alpha$ expression in lung myeloid cells and lung dysfunction}

We finally aimed at determining whether Hif1- $\alpha$ expression in lung myeloid cells correlates with lung dysfunction and inflammation. Table 2 shows that in challenged RAO-affected horses, Hif1- $\alpha$ mRNA expression levels were highly correlated to lung function $\left(\mathrm{X}_{5} \mathrm{H}_{\mathrm{z}}\right)$, arterial pressure of oxygen $\left(\mathrm{PaO}_{2}\right)$, and the percentage of neutrophils in the BALF (\% PMN). The correlations were positive for neutrophil percentages, and negative for $\mathrm{X}_{5} \mathrm{H}_{\mathrm{z}}$ and $\mathrm{PaO}_{2}$. No correlations were observed in challenged healthy horses.

\section{Discussion}

Hif1 is increasingly recognized as a master regulator of inflammatory responses. Recently, it has been demonstrated that Hif1 activity is increased in the lung of mouse models of asthma, as well as in BALF cells from asthmatic patients $[24,25]$. In the present work, we report similar findings in horses suffering from RAO, a disease that shares many similarities with human asthma. We demonstrated that the level of Hif1- $\alpha$ mRNA expression was significantly increased in BALF cells of hay dust-challenged horses and that this effect was more pronounced in RAO-affected than in healthy animals.

The increase in Hif1- $\alpha$ mRNA expression in BALF cells of challenged horses may be explained by the presence of LPS in hay dust. Indeed, it has been previously demonstrated that LPS induces Hif1- $\alpha$ mRNA expression through NF- $\mathrm{kB}$ activation in human monocytes and macrophages under normoxic conditions [26]. While administration of aerosolized LPS to RAO-affected horses induces airway neutrophilia, it is not sufficient to elicit an RAO crisis [5]. At the present time the contribution 
Table 1 Individual results of clinical evaluation

\begin{tabular}{|c|c|c|c|c|c|c|c|c|}
\hline & Horses & $\begin{array}{c}\text { Neutrophils } \\
(\%)\end{array}$ & $\begin{array}{c}\text { Lymphocytes } \\
(\%)\end{array}$ & $\begin{array}{c}\text { Alveolar } \\
\text { macrophages(\%) }\end{array}$ & $\begin{array}{l}\text { Epithelial } \\
\text { cells (\%) }\end{array}$ & $\begin{array}{c}\mathrm{PaO}_{2} \\
(\mathrm{mmHg})\end{array}$ & $\begin{array}{c}\mathrm{X}_{5} \mathrm{H}_{\mathrm{z}} \\
(\mathrm{kPa} / \mathrm{L}-1 / \mathrm{s})\end{array}$ & $\begin{array}{c}\text { Heave } \\
\text { score/8 }\end{array}$ \\
\hline \multirow[t]{9}{*}{ Challenged } & RAO 1 & 49 & 21 & 27 & 3 & 62 & -0.112 & 7 \\
\hline & RAO 2 & 48 & 31 & 23 & 2 & 79 & -0.091 & 6 \\
\hline & RAO 3 & 33 & 17 & 47 & 3 & 88 & -0.045 & 4 \\
\hline & RAO 4 & 34 & 21 & 43 & 5 & 82 & -0.067 & 5 \\
\hline & RAO 5 & 40.5 & 25 & 33 & 1.5 & 86 & -0.107 & 5 \\
\hline & Healthy 1 & 10 & 24 & 62 & 4 & 105 & 0.021 & 2 \\
\hline & Healthy 2 & 12 & 31 & 58 & 1 & 98 & -0.012 & 3 \\
\hline & Healthy 3 & 8 & 29 & 63 & 0 & 92 & 0.013 & 2 \\
\hline & Healthy 4 & 16 & 25 & 57 & 2 & 102 & 0.001 & 4 \\
\hline \multirow[t]{9}{*}{ Unchallenged } & RAO 1 & 5.5 & 33 & 60 & 1.5 & 86 & -0.012 & 3 \\
\hline & RAO 2 & 6 & 16 & 77 & 1 & 92 & -0.006 & 3 \\
\hline & RAO 3 & 4 & 29 & 65 & 2 & 98 & 0.007 & 2 \\
\hline & RAO 4 & 2 & 37 & 60 & 1 & 108 & -0.012 & 2 \\
\hline & RAO 5 & 4.5 & 19 & 71 & 5.5 & 95 & -0.001 & 3 \\
\hline & Healthy 1 & 2 & 23 & 73 & 2 & 98 & 0.028 & 2 \\
\hline & Healthy 2 & 1.5 & 19 & 78.5 & 1 & 104 & -0.004 & 2 \\
\hline & Healthy 3 & 1 & 31 & 67 & 1 & 110 & 0.003 & 2 \\
\hline & Healthy 4 & 2.5 & 15 & 79.5 & 3 & 109 & 0.011 & 2 \\
\hline
\end{tabular}

of LPS to disease severity remains unclear. Yet, emerging evidence suggests that a synergistic effect may exist between inhaled LPS and organic dust particulates. Hif1 activation could also be enhanced by other components present in the hay dust, such as Alternaria spores, $\beta$ -

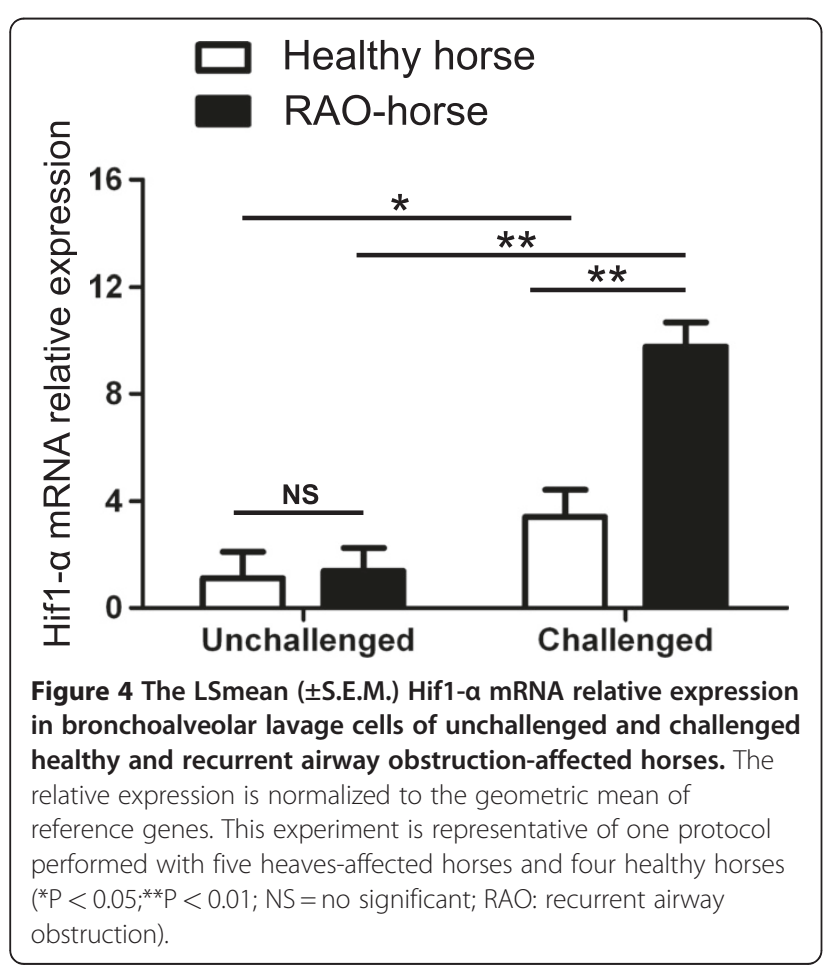

Glucans, which also could activate NF- $\mathrm{B}[27,28]$, even though this hypothesis will require further testing. From this first study, we suggest that LPS or other components present in hay dust may upregulate Hif1- $\alpha$ gene expression via NF- $\mathrm{kB}$ activation in both healthy and RAO-affected horses, with a more pronounced effect in $\mathrm{RAO}$-affected horses. It is well known that NF- $\mathrm{BB}$ activation and hypoxia synergistically activate Hif1 [29]. Whereas NF- $\mathrm{BB}$ increases Hif1- $\alpha$ mRNA expression through fixation on a NF- $\mathrm{kB}$ site in the promoter of the Hif1- $\alpha$ gene, hypoxia post-translationally stabilizes the Hif1- $\alpha$ protein [29]. Accordingly, it has previously been shown that NF- $\mathrm{kB}$ activity is significantly increased in the lungs of RAO-affected horses during crisis when compared to unchallenged healthy horses [30]. Moreover, during RAO crises, inflammation induces a hypoxic environment in the lung tissues, which is a consequence of decreased perfusion, bronchial edema and increase in metabolic activity of recruited inflammatory cells. Furthermore, as illustrated by our clinical results, inflammation-induced local tissue hypoxia may be reinforced by the fact the horses in crisis usually become hypoxemic. Given that Hif1- $\alpha$ mRNA expression was significantly higher in challenged RAO-affected horses than in healthy subjects, it is possible that during the challenge, healthy horses, unlike RAO-affected horses, do not develop enough lung inflammation to induce hypoxia and thereby to increase Hif1 activity. A synergy between NF- $\mathrm{kB}$ activation and hypoxia in inflamed airways might thereby potentiate Hif1 activation in RAO. 


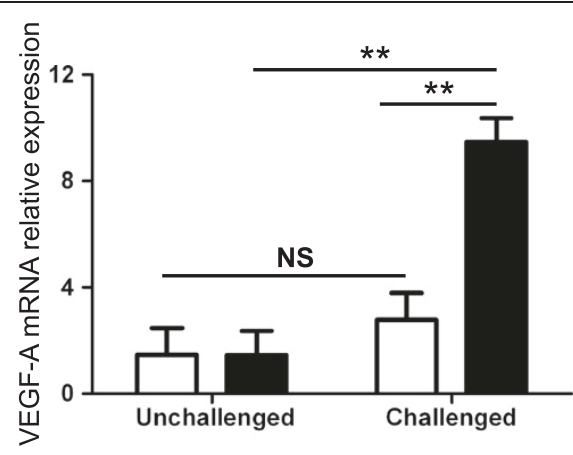

Healthy horse

RAO-horse
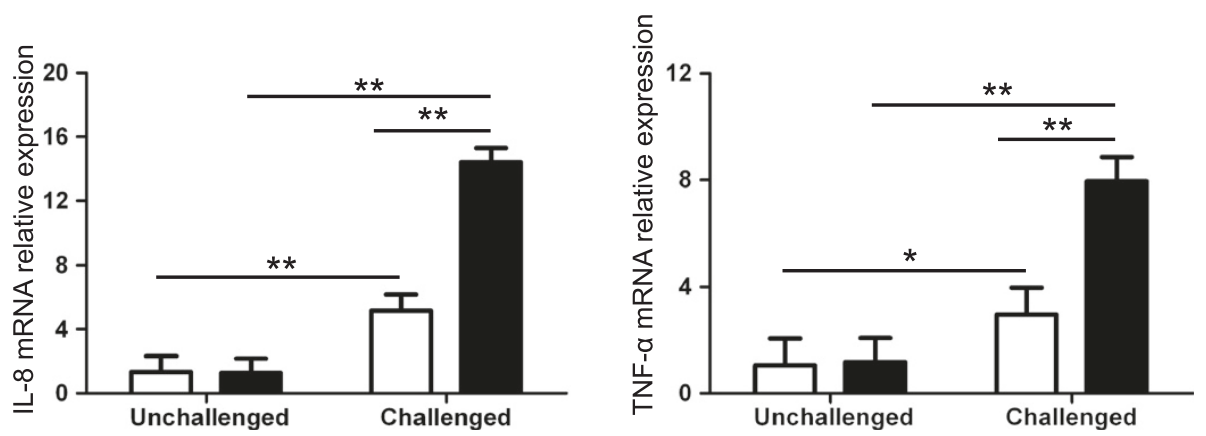

Figure 5 The LSmean ( \pm S.E.M) relative mRNA expression of the VEGF-A , IL-8 and TNF-a genes in bronchoalveolar lavage cells of unchallenged and challenged healthy and recurrent airway obstruction-affected horses. The relative expression is normalized to the geometric mean of reference genes. This experiment is representative of one protocol performed with five heaves-affected horses and four healthy horses $\left({ }^{*} \mathrm{P}<0.05 ;{ }^{* *} \mathrm{P}<0.01\right.$; NS = no significant; $\mathrm{RAO}$ : recurrent airway obstruction).

Further studies should be conducted to directly verify this hypothesis.

The observed increase in Hif1- $\alpha$ mRNA expression in BALF cells of hay dust-exposed horses did not necessarily imply that Hif1 transcriptional activity was increased. To estimate in vivo whether Hif1 was transcriptionally active, we could evaluated the expression of known Hif1 target genes. Hay dust challenge induced a significant increase in IL- 8 and TNF- $\alpha$ mRNA expression in healthy and RAO-affected horses, and this increase was significantly more pronounced in RAO-affected horses. However, only challenged RAO-affected horses showed increased VEGF-A expression. The use of a Hif1- $\alpha$ inhibitor indicated that VEGF-A mRNA and IL-8 mRNA were highly regulated by Hif1 in hay dust stimulatedmonocytes in vitro, in line with reports that Hif1 is able to regulate VEGF-A and IL-8 in human and murine macrophages [31]. However, the regulation of TNF $\alpha$ -
mRNA expression in monocytes after hay dust stimulation was only weakly Hif1 dependent. It is likely that hay dust-induced TNF- $\alpha$ mRNA expression is mainly under the control of other transcription factor such as NF- $\mathrm{KB}$. Following LPS stimulation, Hif1 can induce TNF- $\alpha$ transcription by direct fixation to the TNF- $\alpha$ gene promoter [32]. Yet NF-kB may also induce the transcriptional activation of TNF- $\alpha$ independently of Hif1 [33].

In an in vitro study, Laan and coll. [34] reported that IL-8 and TNFo- play a role in RAO. In equine AM stimulated with a hay dust solution, the expression of these two cytokines is significantly increased in RAO horses compared to healthy horses [34,35]. In rabbits, lung hypoxia was shown to promote IL-8 production from AM [36]. Moreover Franchini et al. [37] have suggested that $\mathrm{AM}$ are implicated in the initial inflammatory reaction, since they demonstrated that release of IL- 8 by AM was required for neutrophil attraction. Taken together, these

Table 2 Correlation between Hif1-a mRNA expression and clinical parameters

\begin{tabular}{|c|c|c|c|c|}
\hline & Status & Hif1-a mRNA/Neutrophils (\%) & Hif1-a mRNA/PaO $2(\mathrm{mmHg})$ & Hif1-a mRNA/ $\mathrm{X}_{5} \mathrm{H}_{\mathrm{Z}}\left(\mathrm{kPa} / \mathrm{L}^{-1} / \mathrm{s}\right)$ \\
\hline \multirow[t]{2}{*}{ Challenged } & Healthy $(n=4)$ & $r=-0.519$ & $r=0.231$ & $r=-0.634$ \\
\hline & RAO-affected $(n=5)$ & $r=0.863(*)$ & $r=-0.881\left(^{*}\right)$ & $r=-0.844(*)$ \\
\hline
\end{tabular}

Coefficient of correlations (r) between Hif1-a mRNA levels in bronchoalveolar lavage (BAL) cells and neutrophil percentages in BALF, reactance at $5 \mathrm{H}_{z}\left(\mathrm{X}_{5} \mathrm{H}_{\mathrm{z}}\right)$, and arterial pressure of oxygen $\mathrm{PaO}_{2}$. These values were measured separately in challenged healthy and recurrent airway obstruction-affected horses. ( $\left.{ }^{*} \mathrm{P}<0.05\right)$ 
findings may suggest that in RAO-affected horses, the exacerbation of Hif1 activation in AM might be the initial response to airborne challenges, followed by an increase of IL-8 cytokine production and neutrophil invasion.

Currently, we have no information about the role played by VEGF-A in heaves. VEGF-A is a potent stimulator of vascular angiogenesis, permeability, and remodeling that also plays important roles in wound healing and tissue cytoprotection [38]. The regulation of vascular permeability is essential for inflammatory processes in airways, especially in the course of chronic lung diseases [39]. In humans beings and mice, VEGF-A is involved in the pathophysiology of bronchial asthma $[39,40]$. Given the similarities between RAO and asthma it may be speculated that VEGF-A could play an important role in RAO pathophysiology.

The expression of these three cytokines positively correlated in vitro and in vivo with that of Hif1- $\alpha$. Even though our in vitro observations suggest that Hif1 activity in monocytes may contribute to expression of these cytokines in vivo, we do not rule out a possible involvement of Hif1 in other cell types.

Moreover even if monocytes are precursors of AM, they are not terminally differentiated cells. Therefore, some differences may exist in terms of regulation of Hif1 expression and activity between monocytes and AM. For instance, unlike AM, monocytes are unable to phagocyte and cytokine production and expression of surface molecules is sometimes different [41]. However, it is well known in others species that Hif1- $\alpha$ is expressed by AM [42] and that LPS can induce Hif1- $\alpha$ in macrophage [34,43]. It is thus highly likely that, like in monocytes, Hif1- $\alpha$ may be expressed by equine AM after hay dust challenge. Given the causative role proposed for AM in RAO, increased Hif1- $\alpha$ activity in AM following hay dust exposure might thus be responsible for crisis induction in RAO affected- horses.

It could also be worthwhile testing Hif1- $\alpha$ activity in equine neutrophils after hay dust stimulation. Indeed in mice, LPS stimulation can induce Hif1 activation in lung neutrophils [44]. After hay dust exposure, BALF neutrophil percentage increases only in RAO-affected horse and positively correlate with Hif1- $\alpha$ mRNA expression. Thus, it is possible that in RAO-affected horses, hay dust-induced neutrophil influx in the lung could also contribute to upregulated Hif1 activity.

Finally, we have also shown that in challenged RAOaffected horses the level of Hif1- $\alpha$ expression in BALF cells correlated with the degree of lung dysfunction. It will be worthwhile testing whether pharmacological inhibition of Hif1 in RAO-affected horses may impact on disease parameters. Supporting the relevance of this approach, it was shown that inhibition of Hif1 in mice using either pharmacological inhibition or conditional gene deletion significantly reduces airway inflammation in models of asthma [24,25].

\section{Conclusion}

In summary, this study demonstrates that hay dust may activate Hif1 in horse myeloid cells. It further shows that lung myeloid cells display increased Hif1 activation upon hay dust challenge in RAO-affected horses compared to healthy horses, and that this activation correlates with disease severity. Our results thus suggest that it would be worthwhile testing the potential therapeutic benefit of pharmacological Hif1 inhibition in RAO.

\section{Methods}

\section{Experimental animals}

Five RAO horses with a history of recurrent episodes of respiratory distress when exposed to dusty stable environment ( 3 females and 2 geldings, median; ranges, 14.5; 9-22 years) and four healthy controls ( 1 female and 3 geldings, median; ranges, 17.5 ; $11-28$ years) were investigated in the study. All horses affected by RAO showed recurrent clinical signs for several years and were therefore defined as chronically affected. Several months before the experiment began, horses were dewormed using ivermectin and vaccinated against tetanus and equine influenza. All experiments were conducted with approval of the Institutional Animal Care and Use Committee of the University of Liège.

\section{Experimental protocol in vivo}

Both groups of horses (RAO and control horses) were maintained on pasture 3 months before the beginning of the study to ensure the RAO horses were in clinical remission at the start of the experiment. All clinical and functional tests were performed on control and RAO horses in the steady-state (after pasture) and during the RAO crisis (3 weeks after the onset of the natural challenge with moldy hay) [45]. Six weeks separated the two testing periods (Figure 6). The clinical signs in horses were scored by a masked observer according to a previously reported system [46]. This protocol was approved by the Ethics Committee of the University of Liege.

\section{Pulmonary function tests}

Pulmonary function was evaluated at rest with an equine impulse oscillometry system (IOS) Master Screen (VIASYS Healthcare GmbH, Höchberg, Germany), validated for the horse $[47,48]$. Only the reactance at $5 \mathrm{~Hz}$ was used because it is the most sensitive for measuring changes in mechanical ventilation in the lower respiratory system. Before each experiment, the system was calibrated and the tests were performed without any prior sedation. 


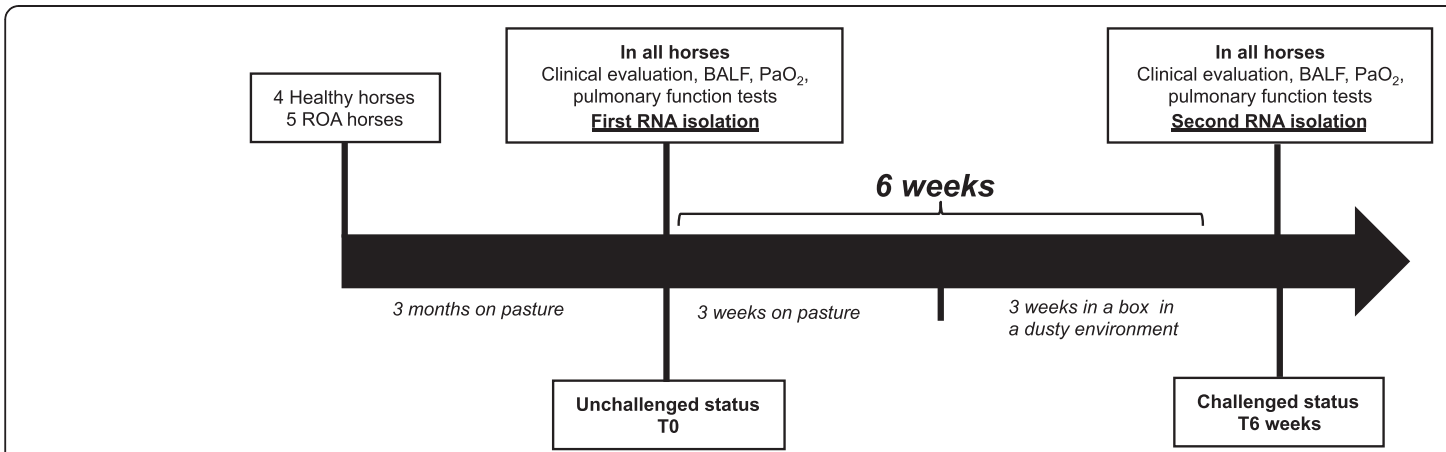

Figure 6 Protocol in vivo: experimental design.

\section{Arterial blood gas analysis}

Arterial blood was anaerobically collected in heparinized syringes by arterial puncture of the carotid artery with a 20 G 0.9 x 40 mm needle (Terumo Europe, Leuven, Belgium). The blood was immediately analyzed for partial pressure of oxygen and carbon dioxide $\left(\mathrm{PaO}_{2}\right.$ and $\left.\mathrm{PaCO}_{2}\right)$ with the use of an autocalibrated blood gas analyzer (OPTI CCA; Osmetech, Roswell, Georgia, USA). The results were corrected for the patient's body temperature.

\section{Bronchoalveolar lavage fluid cell isolation}

The horses were sedated with IV romifidine, $(0.01 \mathrm{mg} / \mathrm{kg}$; Sedivet; Boehringer Ingelheim, Ingelheim, Germany), and butorphanol (0.02 mg/kg; Torbugesic; Fort Dodge, Wyeth, Madison, New Jersey, USA). Bronchoalveolar lavage was performed by instillation of six boluses of $60 \mathrm{~mL}$ of sterile saline with EDTA $(0.6 \mathrm{mM})$ at $37^{\circ} \mathrm{C}$ into the working channel of a fiberoptic endoscope $(250 \mathrm{~cm} \times 9 \mathrm{~mm}$, Pentax, Breda, The Netherlands) wedged into a bronchus. The samples recovered from the six syringes were pooled and immediately placed on ice. An aliquot was collected for cytological analysis and differential cell counts.

Bronchoalveolar lavage fluid cells were collected by centrifugation for $7 \mathrm{~min}$ at $300 \mathrm{~g}$. The pellet was filtered and washed twice in phosphate buffered saline (PBS). Cells were resuspended in lysis buffer RA1 (NucleoSpin ${ }^{\circledR}$ RNAII; Macherey-Nagel, Düren, Germany) according to the manufacturer's instructions and stored at $-80^{\circ} \mathrm{C}$ until RNA isolation.

\section{Production of hay dust suspension}

Hay dust suspensions were prepared as previously described by Pirie et al.[49]. Briefly, visibly moldy patches of hay were manually agitated and the dust collected. Fine dust $(1 \mathrm{~g})$ was suspended in $1 \mathrm{~mL}$ isotonic saline $(0.9 \% \mathrm{NaCl})$ solution and assayed for LPS content. The quantity of LPS present in the hay dust suspension (48234 EU/mL) was measured by ELISA (ENdoLISA ${ }^{\circledR}$; Hyglos, Bernried am Starnberger See, Germany). The hay dust suspension was diluted in culture medium to a concentration of $1 \mu \mathrm{g} / \mathrm{mL}$ (LPS content: $48.234 \mathrm{EU} / \mathrm{mL}$ ).
Isolation of peripheral blood monocytes

Because they required large numbers of cells, these experiments were conducted on equine monocytes as a model of equine myeloid cells. Blood was collected from three healthy adult horses into $2 \mathrm{mM}$ EDTA. The blood was diluted twice with PBS and layered on Histopaque1077 (Sigma Diagnostics, St Louis, MO). After centrifugation at $400 \mathrm{~g}$ for $25 \mathrm{~min}$ at $4^{\circ} \mathrm{C}$, the mononuclear cells were aspirated and washed twice with ice-cold PBSEDTA. The cell pellet was suspended in RPMI-1640 with $10 \%$ inactivated fetal bovine serum (FBS), penicillin (50 U/mL), and streptomycin $(50 \mu \mathrm{g} / \mathrm{mL})$ and after was incubated at $37^{\circ} \mathrm{C}$ in $5 \% \mathrm{CO} 2$ for two hours to permit adherence of monocytes. Nonadherent cells were removed by three washes with PBS. The adherent cell population consisted of $>85 \%$ monocytes. The monocytes were re-suspended in RPMI-1640 $\left(1 \times 10^{6}\right.$ cells $\left./ \mathrm{mL}\right)$ and seeded in a 6-well culture plate. Each well received 1 of the following 4 treatments: PBS, hay dust suspension $(1 \mu \mathrm{g} / \mathrm{mL})$, Noscapine hydrochloride (150 $\mu \mathrm{M}$; Sigma-Aldrich, Saint Louis, MO, USA) or Noscapine hydrochloride $(150 \mu \mathrm{M})$ combined with a hay dust suspension $(1 \mu \mathrm{g} / \mathrm{mL})$. In order to model a stimulation as close as possible to the in vivo situation, we chose to stimulate monocytes with hay dust suspensions.

Noscapine, an inhibitor of Hif1 activity, was added 1 hour before the hay dust suspensions (Figure 7).[50,51] One, two and four hours after treatments, the monocytes were collected, washed with PBS and lysed in buffer RA1 (NucleoSpin ${ }^{\circledR}$ RNAII; Macherey-Nagel, Düren, Germany) according to the manufacturer's instructions and stored at $-80^{\circ} \mathrm{C}$ until RNA isolation.

\section{RNA isolation from blood monocytes and BALF cells and real-time RT-PCR}

Total RNA from blood monocytes and BALF cells was extracted using NucleoSpin ${ }^{\circledR}$ RNAII (Macherey-Nagel, Düren, Germany) in presence of Dnase.

Total RNA quantity was measured using a Nanodrop ${ }^{\circledR}$ ND-1000 spectrophotometer (Isogen Life Science B.V., 


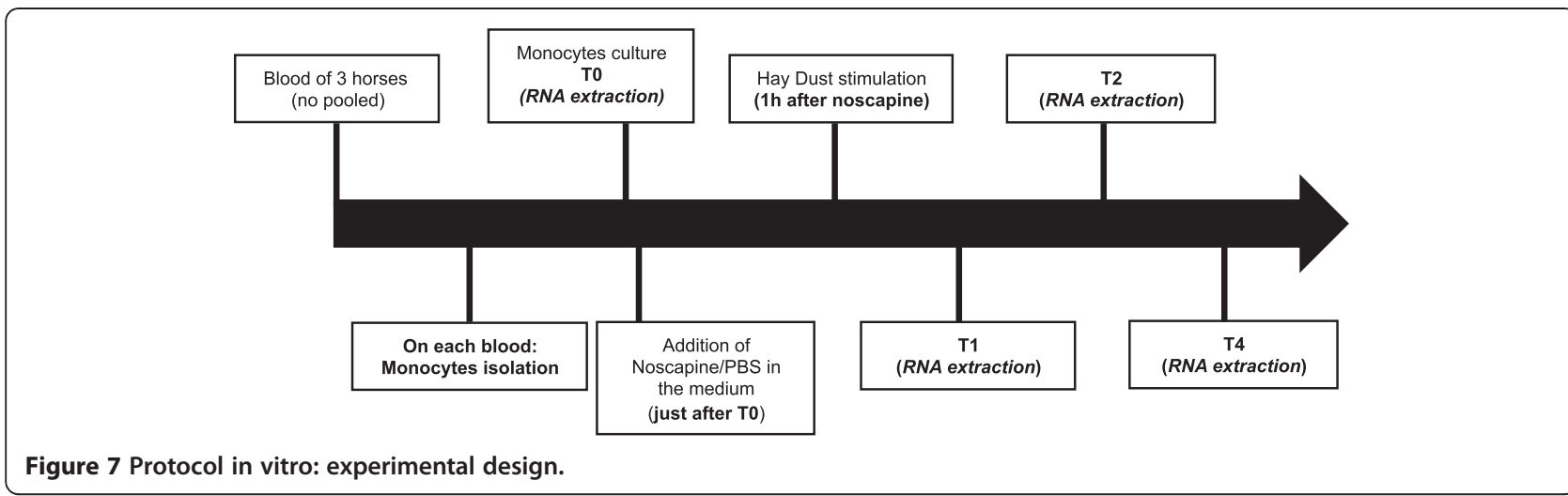

Netherlands). One microgram of RNA was used for each reverse transcription using the First Strand cDNA Synthesis kit (Roche, Basel, Switzerland).

Quantitative PCR reactions were performed with IQ Sybr Green Supermix (Bio-Rad Laboratores, Inc., Marne-la-Coquette, France). The reaction master mix was prepared as recommended by the manufacturer.

To determine whether hay dust-induced Hif1 $\alpha$ mRNA upregulation results in increased Hif1 activity in equine monocytes. We evaluated Hif1 activation by studying the level of expression of the Hif1 target genes VEGF-A, IL- 8 and TNF- $\alpha$. We stimulated or not equine monocytes with hay dust and relative expression of VEGF-A, IL- 8 and TNF- $\alpha$ was assessed by RT-qPCR. Primers for the targets: Hif1- $\alpha$, IL-8, VEGF-Alpha, TNF-alpha and reference genes: ACTB ( $\beta$-actin), GAPDH (glycéraldhéyde-3 phosphate dehydrogenase), HPRT (hypoxanthine phosphoribosyltransferase), RPL32 (ribosomal protein L32) and SDHA (succinate dehydrogenase complex subunit A) were designed with Primer3Plus software and purchased from Eurogentec (Liège, Belgique). For each investigated gene, GenBank accession numbers, primer sequences and product size are given in Table 3. Due to lack of sequence in NCBI database, horse RPL32 sequence was retrieved by probing UCSC horse genome sequence with human RPL32 mRNA sequence. Primers were then designed in conserved regions by using Primer3Plus software.

The cDNA were amplified and quantified in the ICycler iQ real-time PCR detection system (Bio-Rad Laboratories N.V., Nazareth Eke, Belgium). At the end of each qPCR, a melt curve was generated to confirm that a single sequence was amplified for each primer pair. Agarose gel electrophoresis and the melting curve were used to assess the specificity of gene amplification. To confirm reproducibility, all samples were analyzed in duplicate on the plate. The entire experiments were performed in triplicate on independent samples. For each qPCR data analysis, reference genes were analyzed in parallel.

\section{Data analysis}

Real-time $\mathrm{qPCR}$ results were analyzed using the QBASE + software (Biogazelle, Ghent, Belgium), including the geNorm tool to assess reference genes stability (Table 4). Internal control genes were ranked according to their gene-stability measure M. M is computed by determining, for every control gene, the average pairwise variation with all other control genes as the standard deviation of the logarithmically transformed expression ratios [52]. Genes with the lowest $M$ values have the most stable expression. This method constitutes an improvement over the classical delta-delta-Ct method, since it takes into account multiple reference genes, resulting in improved data normalization. The values obtained from the in vitro and in vivo study were normalized with the two most stable reference genes RPL32 and HPRT.

\section{Statistical analysis}

All data are presented as least square means (LSmeans) \pm associated S.E.M. (standard error of the mean) for quantitative PCR results. The residual distribution was normally distributed.

During the in vitro study, all four genes were analyzed using the same mixed model (SAS, Cary, NC). The models included the "time" factor (with levels T0, T1, T2 and T4), the "treatment" factor (PBS, dust, noscapine, dust + noscapine) and the interaction between these two factors. There was no effect of "time" in the in vitro kinetic. Correlations between successive measurements made on the same individual were taken into account using an auto-regressive residuals structure. The in vitro experiments were repeated at least three times. $\mathrm{P}<0.05$ was considered significant.

The clinical values, were analyzed using the PROC GLM procedure of the SAS package (SAS Institute, Cary, NC) and a model including "disease status" (healthy vs RAO), "treatment" (no challenged vs challenged), and their interactions as fixed effects. Separate estimates of the least square means of the states, the 
Table 3 Primer sequences used for RT-qPCR validation procedure

\begin{tabular}{|c|c|c|c|c|}
\hline \multirow[t]{2}{*}{ Genes } & \multirow[t]{2}{*}{ Equine accession number } & \multicolumn{2}{|r|}{ Primers sequence } & \multirow[t]{2}{*}{ Product size (bp) } \\
\hline & & 5 - - & -——————-——- & \\
\hline \multicolumn{5}{|l|}{ Targets } \\
\hline \multirow[t]{2}{*}{ Hif1-a } & LOC100061166 & Forward & ctcaaatgcaagaacctgctc & 108 \\
\hline & & Reverse & ttccataccatcttttgtcactg & \\
\hline \multirow[t]{2}{*}{ VEGF-a } & NM_001081821 & Forward & tggcagaaggagagcataaaa & 123 \\
\hline & & Reverse & actcgatctcatcggggtact & \\
\hline \multirow[t]{2}{*}{ IL-8 } & NM_001083951 & Forward & aatgagagcgattgagagtgg & 127 \\
\hline & & Reverse & caaaaacgcctgcacaataat & \\
\hline \multirow[t]{2}{*}{ TNF-a } & EU438779 & Forward & agcctcttctecttcctcctt & 123 \\
\hline & & Reverse & cagagggttgattgactggaa & \\
\hline \multicolumn{5}{|c|}{ Housekeeping gene } \\
\hline \multirow[t]{2}{*}{ ACTB } & NM_001081838.1 & Forward & ggacctgacggactacctc & 81 \\
\hline & & Reverse & cacgcacgatttccctctc & \\
\hline \multirow[t]{2}{*}{ GAPDH } & NM_001163856 & Forward & atctgacctgccgectggag & 70 \\
\hline & & Reverse & cgatgcctgcttcaccaccttc & \\
\hline \multirow[t]{2}{*}{ HPRT } & XM_001490189.2 & Forward & aattatggacaggactgaacgg & 121 \\
\hline & & Reverse & ataatccagcaggtcagcaaag & \\
\hline \multirow[t]{2}{*}{ RPL32 } & None & Forward & gggagcaataagaaaacgaagc & 113 \\
\hline & & Reverse & cttggaggagacattgtgagc & \\
\hline \multirow[t]{2}{*}{ SDHA } & XM_001490889.3 & Forward & gaggaatggtctggaatactg & 91 \\
\hline & & Reverse & gcctctgctccataaatcg & \\
\hline
\end{tabular}

treatments and the interaction between the disease status and treatments effects have been obtained for each clinical parameter. $\mathrm{P}<0.05$ was considered significant.

During the in vivo experiment, relative expression values, as obtained from qBasePlus software, were analyzed using the PROC GLM procedure of the SAS package (SAS Institute, Cary, NC) and a model including "disease status" (healthy vs RAO), "treatment" (no challenged vs challenged), "gene" (IL-8, Hif1, TNF- $\alpha$, VEGF-A) and their interactions as fixed effects. Separate estimates of the least square means of the states, the treatments and the interaction between the disease status and treatments effects have been obtained for each gene". P $<0.05$ was considered significant.

To study the correlation between the genes expression and the physiological parameters (the percentage of neutrophils, $\mathrm{X}_{5} \mathrm{H}_{\mathrm{z}}$ and $\mathrm{PaO}_{2}$ ) standard least-square linear

Table 4 Reference genes stability according to geNorm

\begin{tabular}{ccc}
\hline Gene symbol & Stability value in vitro (M) & Stability value in vivo (M) \\
\hline HPRT & 0.489 & 0.594 \\
\hline SDHA & 0.784 & 0.711 \\
\hline RPL32 & 0.565 & 0.512 \\
\hline GAPDH & 0.625 & 0.888 \\
\hline ACTB & 0.883 & 0.904
\end{tabular}

Genes with the lowest $\mathrm{M}$ values have the most stable expression. regressions were carried out. Coefficients of correlation of pearson ( $r$ ) were presented as measures of linear association for regression relationships. Significant differences of the slopes from zero were determined using a two-tailed Student's $t$ test. $\mathrm{P}<0.05$ was considered significant.

\section{Abbreviations}

ACTB: $\beta$-actin; ATP: Adenosine triphosphate; B2M: $\beta$-2-microglobulin; BALF: Bronchoalveolar lavage fluid; GAPDH: Glycéraldhéyde-3 phosphate dehydrogenase; Hif: Hypoxia-inducible factor; HPRT: Hypoxanthine phosphoribosyltransferase; HRE: Hypoxia response element; IL-1 $\beta$ : Interleukin 1-B; IL-8: Interleukin 8; IOS: Impulse oscillometry system;

LPS: Lipopolysaccharides; AM: Alveolar macrophage; NF- B: Nuclear factor Bi $\mathrm{PaO}_{2}$ : Arterial blood pressure oxygen; PBS: Phosphate buffered saline; PHD: Prolyl hydroxylases; PMN: Polymorphonuclear neutrophils; RAO: Recurrent airway obstruction; RPL32: Ribosomal protein L32;

SDHA: Succinate dehydrogenase complex subunit; TNF-a: Tumor necrosis factor alpha; $\mathrm{X}_{5} \mathrm{H}_{\mathrm{Z}}$ : Lung resistance.

\section{Competing interest}

This manuscript, in whole or in part, has not been published elsewhere, and has been read and approved by all authors. Sources of extra institutional funding or support have been acknowledged. There are no financial or personal conflicts of interest. The authors represent and warrant that our part of the work as submitted will in no way violate any copyright, or any other right. The authors declare that they have no competing interests.

\section{Authors' contributions}

MT performed most of the experiments. LF helped to isolate the equine monocytes. DP participated in the qBase and statistical analysis. $\mathrm{FB}, \mathrm{PL}$, participated in the design of the study. FF performed the statistical analysis. $\mathrm{CD}$ helped to draft the manuscript. All authors read and approved the final manuscript. 


\section{Acknowledgments}

We thank Dr Audrey Fraipont, Dr Eve Ramery and Jean-Clément Bustin for their help with horse management, and Raja Fares, Cédric François and Ilham Sbai for technical and secretarial assistance. M. Toussaint is a research fellow at the Fonds pour la formation à la Recherche dans I'Industrie et dans I'Agriculture (FRIA; Belgium).

\section{Author details}

'Laboratory of Cellular and Molecular Physiology, GIGA-Research and Faculty of Veterinary Medicine, University of Liège, B34-Avenue de l'Hôpital, 1, 4000, Liège, Belgium. ${ }^{2}$ Department of Animal productions, Faculty of Veterinary Medicine, University of Liège, B42-Boulevard de Colonster, 20, 4000, Liège, Belgium.

Received: 6 February 2012 Accepted: 7 May 2012 Published: 23 May 2012

\section{References}

1. Derksen FJ, Scott JS, Miller DC, Slocombe RF, Robinson NE: Bronchoalveolar lavage in ponies with recurrent airway obstruction (heaves). Am Rev Respir Dis 1985, 132(5):1066-1070.

2. Lowell FC: Observations on Heaves. An Asthma-Like Syndrome in the Horse. J Allergy 1964, 35:322-330.

3. Robinson NE: International Workshop on Equine Chronic Airway Disease. Michigan State University 16-18 June 2000. Equine Vet J 2001, 33(1):5-19.

4. Mair TS: Changing concepts of COPD. Equine Vet J 1995, 27(6):402-403.

5. Pirie RS, Dixon PM, McGorum BC: Endotoxin contamination contributes to the pulmonary inflammatory and functional response to Aspergillus fumigatus extract inhalation in heaves horses. Clin Exp Allergy 2003, 33 (9):1289-1296.

6. Wagner B: IgE in horses: occurrence in health and disease. Vet Immunol and Immunop 2009, 132(1):21-30

7. Lavoie JP, Maghni K, Desnoyers M, Taha R, Martin JG, Hamid QA: Neutrophilic airway inflammation in horses with heaves is characterized by a Th2-type cytokine profile. Am J Respir Crit Care Med 2001, 164(8 Pt 1):1410-1413.

8. Ainsworth DM, Grunig G, Matychak MB, Young J, Wagner B, Erb HN, Antczak DF: Recurrent airway obstruction (RAO) in horses is characterized by IFNgamma and IL-8 production in bronchoalveolar lavage cells. Vet Immunol and Immunop 2003, 96(1-2):83-91.

9. Cordeau ME, Joubert P, Dewachi O, Hamid Q, Lavoie JP: IL-4, IL-5 and IFNgamma mRNA expression in pulmonary lymphocytes in equine heaves. Vet Immunol and immunop 2004, 97(1-2):87-96.

10. Horohov DW, Beadle RE, Mouch S, Pourciau SS: Temporal regulation of cytokine mRNA expression in equine recurrent airway obstruction. Vet Immunol and Immunop 2005, 108(1-2):237-245.

11. Kleiber C, McGorum BC, Horohov DW, Pirie RS, Zurbriggen A, Straub R: Cytokine profiles of peripheral blood and airway CD4 and CD8 T lymphocytes in horses with recurrent airway obstruction. Vet Immunol and Immunop 2005, 104(1-2):91-97.

12. Karhausen J, Haase VH, Colgan SP: Inflammatory hypoxia: role of hypoxiainducible factor. Cell Cycle 2005, 4(2):256-258.

13. Jaakkola P, Mole DR, Tian YM, Wilson MI, Gielbert J, Gaskell SJ, Kriegsheim A, Hebestreit HF, Mukherji M, Schofield CJ, et al: Targeting of HIF-alpha to the von Hippel-Lindau ubiquitylation complex by O2-regulated prolyl hydroxylation. Science 2001, 292(5516):468-472.

14. McNeill LA, Hewitson KS, Claridge TD, Seibel JF, Horsfall LE, Schofield CJ: Hypoxia-inducible factor asparaginyl hydroxylase (FIH-1) catalyses hydroxylation at the beta-carbon of asparagine-803. Biochem J 2002, 367 (3):571-575.

15. Saadi S, Wrenshall LE, Platt JL: Regional manifestations and control of the immune system. FASEB J 2002, 16(8):849-856.

16. Sitkovsky M, Lukashev D: Regulation of immune cells by local-tissue oxygen tension: HIF1 alpha and adenosine receptors. Nat Rev Immunol 2005, 5(9):712-721.

17. Semenza GL: HIF-1: mediator of physiological and pathophysiological responses to hypoxia. J Appl Physiol 2000, 88(4):1474-1480.

18. Rius J, Guma M, Schachtrup C, Akassoglou K, Zinkernagel AS, Nizet V, Johnson RS, Haddad GG, Karin M: NF-kappaB links innate immunity to the hypoxic response through transcriptional regulation of HIF-1alpha. Nature 2008, 453(7196):807-811.
19. Jantsch J, Wiese M, Schodel J, Castiglione K, Glasner J, Kolbe S, Mole D, Schleicher U, Eckardt KU, Hensel M, et al: Toll-like receptor activation and hypoxia use distinct signaling pathways to stabilize hypoxia-inducible factor 1alpha (HIF1A) and result in differential HIF1A-dependent gene expression. J Leukoc Biol 2011, 90(3):551-562.

20. Mahabeleshwar GH, Kawanami D, Sharma N, Takami Y, Zhou G, Shi H, Nayak $L$, Jeyaraj D, Grealy R, White M, et al: The myeloid transcription factor KLF2 regulates the host response to polymicrobial infection and endotoxic shock. Immunity 2011, 34(5):715-728.

21. Hellwig-Burgel T, Rutkowski K, Metzen E, Fandrey J, Jelkmann W: Interleukin-1 beta and tumor necrosis factor-alpha stimulate DNA binding of hypoxia-inducible factor-1. Blood 1999, 94(5):1561-1567.

22. Blouin CC, Page EL, Soucy GM, Richard DE: Hypoxic gene activation by lipopolysaccharide in macrophages: implication of hypoxia-inducible factor 1alpha. Blood 2004, 103(3):1124-1130.

23. Gorlach A, Bonello S: The cross-talk between NF-kappaB and HIF-1: further evidence for a significant liaison. Biochem J 2008, 412 (3):17-19.

24. Huerta-Yepez S, Baay-Guzman GJ, Garcia-Zepeda R, Hernandez-Pando R, Vega Ml, Gonzalez-Bonilla C, Bonavida B: 2-Methoxyestradiol (2-ME) reduces the airway inflammation and remodeling in an experimental mouse model. Clin Immunol 2008, 129(2):313-324.

25. Huerta-Yepez S, Baay-Guzman GJ, Bebenek IG, Hernandez-Pando R, Vega MI, Chi L, Riedl M, Diaz-Sanchez D, Kleerup E, Tashkin DP, et al: Hypoxia Inducible Factor promotes murine allergic airway inflammation and is increased in asthma and rhinitis. Allergy 2011, 66(7):909-918.

26. Frede S, Stockmann C, Freitag P, Fandrey J: Bacterial lipopolysaccharide induces HIF-1 activation in human monocytes via p44/42 MAPK and NFkappaB. Biochem J 2006, 396(3):517-527.

27. Ashitani J, Kyoraku Y, Yanagi S, Matsumoto N, Nakazato M: Elevated levels of beta-D-glucan in bronchoalveolar lavage fluid in patients with farmer's lung in Miyazaki, Japan. Respiration 2008, 75(2):182-188.

28. McCann F, Carmona E, Puri V, Pagano RE, Limper AH: Macrophage internalization of fungal beta-glucans is not necessary for initiation of related inflammatory responses. Infect Immun 2005, 73 (10):6340-6349.

29. Mi Z, Rapisarda A, Taylor L, Brooks A, Creighton-Gutteridge M, Melillo G, Varesio L: Synergystic induction of HIF-1alpha transcriptional activity by hypoxia and lipopolysaccharide in macrophages. Cell Cycle 2008, 7 (2):232-241.

30. Sandersen C, Bureau F, Turlej R, Fievez L, Dogne S, Kirschvink N, Lekeux P: p65 Homodimer activity in distal airway cells determines lung dysfunction in equine heaves. Vet Immunol and Immunop 2001, 80 (3-4):315-326.

31. Fang HY, Hughes R, Murdoch C, Coffelt SB, Biswas SK, Harris AL, Johnson RS, Imityaz HZ, Simon MC, Fredlund E, et al: Hypoxia-inducible factors 1 and 2 are important transcriptional effectors in primary macrophages experiencing hypoxia. Blood 2009, 114(4):844-859.

32. Liu FQ, Liu Y, Lui VC, Lamb JR, Tam PK, Chen Y: Hypoxia modulates lipopolysaccharide induced TNF-alpha expression in murine macrophages. Exp Cell Res 2008, 314(6):1327-1336.

33. An HJ, Kim IT, Park HJ, Kim HM, Choi JH, Lee KT: Tormentic acid, a triterpenoid saponin, isolated from Rosa rugosa, inhibited LPS-induced iNOS, COX-2, and TNF-alpha expression through inactivation of the nuclear factor-kappab pathway in RAW 264.7 macrophages. Int Immunopharmacol 2011, 11(4):504-510.

34. Laan $T$, Bull S, Pirie R, Fink-Gremmels J: The role of alveolar macrophages in the pathogenesis of recurrent airway obstruction in horses. J Vet Intern Med 2006, 20(1):167-174

35. Bureau F, Delhalle S, Bonizzi G, Fievez L, Dogne S, Kirschvink N, Vanderplasschen A, Merville MP, Bours V, Lekeux P: Mechanisms of persistent NF-kappa B activity in the bronchi of an animal model of asthma. J Immunol 2000, 165(10):5822-5830.

36. Hirani N, Antonicelli F, Strieter RM, Wiesener MS, Ratcliffe PJ, Haslett C, Donnelly SC: The regulation of interleukin-8 by hypoxia in human macrophages-a potential role in the pathogenesis of the acute respiratory distress syndrome (ARDS). Mol Med 2001, 7(10):685-697.

37. Franchini $M$, Gill U, von Fellenberg R, Bracher VD: Interleukin-8 concentration and neutrophil chemotactic activity in bronchoalveolar lavage fluid of horses with chronic obstructive pulmonary disease following exposure to hay. Am J Vet Res 2000, 61(11):1369-1374. 
38. Hatoum OA, Miura H, Binion DG: The vascular contribution in the pathogenesis of inflammatory bowel disease. Am J Physiol Heart Circ Physiol 2003, 285(5):H1791-1796.

39. Gomulka K, Liebhart J: Vascular endothelial growth factor - structure, function and role in airways inflammation and the clinical course of asthma. Pneumonol Alergol Pol 2009, 77(6):549-553.

40. Lee SY, Kwon S, Kim KH, Moon HS, Song JS, Park SH, Kim YK: Expression of vascular endothelial growth factor and hypoxia-inducible factor in the airway of asthmatic patients. Ann Allergy Asthma Immunol 2006, 97 (6):794-799.

41. Gordon S, Taylor PR: Monocyte and macrophage heterogeneity. Nat Rev Immunol 2005, 5(12):953-964.

42. Ueno M, Maeno T, Nomura M, Aoyagi-Ikeda K, Matsui H, Hara K, Tanaka T, Iso T, Suga T, Kurabayashi M: Hypoxia-inducible factor-1alpha mediates TGF-beta-induced PAl-1 production in alveolar macrophages in pulmonary fibrosis. Am J Physiol Lung Cell Mol Physiol 2011, 300(5): L740-752.

43. Frede S, Stockmann C, Winning S, Freitag P, Fandrey J: Hypoxia-inducible factor (HIF) 1alpha accumulation and HIF target gene expression are impaired after induction of endotoxin tolerance. J Immunol 2009, 182 (10):6470-6476.

44. Schuster DP, Brody SL, Zhou Z, Bernstein M, Arch R, Link D, Mueckler M: Regulation of lipopolysaccharide-induced increases in neutrophil glucose uptake. Am J Physiol Lung Cell Mol Physiol 2007, 292(4):L845-851.

45. Britten KM, Howarth PH, Roche WR: Immunohistochemistry on resin sections: a comparison of resin embedding techniques for small mucosal biopsies. Biotech Histochem 1993, 68(5):271-280.

46. Robinson NE, Olszewski MA, Boehler D, Berney C, Hakala J, Matson C, Derksen FJ: Relationship between clinical signs and lung function in horseswith recurrent airway obstruction (heaves) during a bronchodilator trial. Equine Vet J 2000, 32(5):393-400.

47. Van Erck E, Votion D, Art T, Lekeux P: Qualitative and quantitative evaluation of equine respiratory mechanics by impulse oscillometry. Equine Vet J 2006, 38(1):52-58.

48. van Erck E, Votion D, Art T, Lekeux P: Measurement of respiratory function by impulse oscillometry in horses. Equine Vet J 2004, 36(1):21-28.

49. Pirie RS, McLachlan G, McGorum BC: Evaluation of nebulised hay dust suspensions (HDS) for the diagnosis and investigation of heaves. 1: Preparation and composition of HDS. Equine Vet J 2002, 34(4):332-336.

50. Newcomb EW, Lukyanov Y, Schnee T, Ali MA, Lan L, Zagzag D: Noscapine inhibits hypoxia-mediated HIF-1alpha expression andangiogenesis in vitro:a novel function for an old drug. Int J Oncol 2006, 28 (5):1121-1130.

51. Newcomb EW, Lukyanov Y, Smirnova I, Schnee T, Zagzag D: Noscapine induces apoptosis in human glioma cells by an apoptosis-inducing factor- dependent pathway. Anticancer Drugs 2008, 19(6):553-563.

52. Vandesompele J, De Preter K, Pattyn F, Poppe B, Van Roy N, De Paepe A, Speleman F: Accurate normalization of real-time quantitative RT-PCR data by geometric averaging of multiple internal control genes. Genome Biol 2002, 3(7):RESEARCH0034.

doi:10.1186/1746-6148-8-64

Cite this article as: Toussaint et al:: Increased hypoxia-inducible factor 1 a expression in lung cells of horses with recurrent airway obstruction. BMC Veterinary Research 2012 8:64.

\section{Submit your next manuscript to BioMed Central and take full advantage of:}

- Convenient online submission

- Thorough peer review

- No space constraints or color figure charges

- Immediate publication on acceptance

- Inclusion in PubMed, CAS, Scopus and Google Scholar

- Research which is freely available for redistribution

Submit your manuscript at www.biomedcentral.com/submit 